\title{
PENGARUH MEDIA FLIPCHART TERHADAP KEMAMPUAN MEMBACA ANAK USIA DINI KELOMPOK B TK NEGERI PEMBINA CIAWIGEBANG
}

\author{
Erik Wahyudin \\ STKIP Muhammadiyah Kuningan \\ Email : erikwahyudin12@gmail.com
}

(Received: September 2017; Accepted: Oktober 2017; Published: Desember 2017)

\begin{abstract}
Flipchart is a sheet of an album or calendar that is a bit larger than flipbook, arranged and tied in an order at the top. The paper sheet can be used as a media of teaching and learning, and may be considered as a replacement for the chalkboard or whiteboard. If a sheet is filled up with learning messages, it can be flipped over and the next sheet can be filled with new learningmessages. Flipchart media can only be used for a student group that contains approximately 30 people. This media can be filled with message in the form of letters, drawings, diagrams and figures. Reading for children of kindergarten is basic reading which is one of the aspects of language development that should be developed in kindergarten in her activities such as mentioning vowels and consonants, reading images that have a sentence or a simple word, mentioning objects that have the same sound of the beginning letter, and connecting images with the words. This study aimed to determine (a) the reading ability of early childhood kindergarten Pembina Group B Ciawigebang before the application of flipchart media. (b) the flipchart media application in learning to read in early childhood of Pembina kindergarten Group B Ciawigebang. (c) the flipchart media influence on early childhood reading ability in Pembina kindergarten Group B Ciawigebang. This study used a quantitative approach with the experimental method. The subjects in this study were 24 children in Pembina kindergarten Group B Ciawigebang. Data were collected through observation, testing and documentation. Data were analyzed using t-test. The results of the average post-test are 13 with an increase of 2.2 higher than the average value of the 10.8 pre-test. Based on the results of pre-test and post-test, 12.99 is obtained for tcount value with $d f=23$, consulted with ttable value at $5 \%$ significance level, it is obtained a result of 2.07. These results indicate tcount is greater than the value ttable (12.99> 2.07). Ho was rejected and Ha was accepted. It means that flipchart media affected positively on reading ability of early childhood in Pembina kindergarten Group B Ciawigebang.
\end{abstract}

Keywords: Flipchart Media, Reading Ability, Early Childhood

\begin{abstract}
ABSTRAK
Flipchart adalah lembaran kertas berbentuk album atau kalender yang berukuran agak besar dari flipbook, yang disusun dalam urutan yang diikat pada bagian atasnya. Lembaran kertas tersebut dapat dijadiakan sebagai media pengajaran dan pembelajaran, dan mungkin bisa dianggap sebagai pengganti papan tulis atau white board. Jika lembaran demi lembaran tersebut sudah habis terisi dengan pesan pembelajaran, maka lembaran itu bisa dibalik, kemudian lembar dibaliknya yang masih kosong tersebut bisa diisi dengan pesan pembelajaran. Media ini hanya bisa digunakan untuk kelompok siswa yang berisi sekitar 30 orang. Media flipchart bisa diisi pesan dalam bentuk huruf, gambar, diagram dan angka. Membaca bagi anak Taman Kanak-kanak adalah membaca permulaan yang merupakan salah satu dari aspek perkembangan bahasa yang harus dikembangkan di Taman Kanak-kanak dalam kegiatannnya menyebutkan huruf vokal dan konsonan, membaca gambar yang memiliki kalilmat atau kata sederhana, menyebutkan benda yang memiliki bunyi huruf awal yang sama, dan menghubungkan gambar dengan tulisan. Penelitian ini menggunakan pendekatan kuantitatif dengan metode eksperimen. Subjek dalam penelitian ini adalah anak Kelompok B TK Negeri Pembina Ciawigebang berjumlah 24 anak. Data dikumpulkan melalui observasi, tes dan dokumentasi. Teknik analisis data menggunakan uji t. Hasil penelitian dari rata-rata post-test yaitu 13 dengan peningkatan sebesar 2,2 lebih tinggi dari nilai rata-rata pre-test yaitu 10,8. Berdasarkan hasil pre-test dan post-test diperoleh nilai thitung sebesar 12,99 dengan $\mathrm{dk}=23$ dikonsultasikan dengan nilai ttabel pada taraf signifikasi 5\% diperoleh hasil 2,07. Dari hasil tersebut menunjukkan nilai thitung lebih besar daripada nilai ttabel $(12,99>2,07)$ hasilnya tolak Ho dan Ha diterima artinya media flipchart berpengaruh positif terhadap kemampuan membaca anak usia dini Kelompok B TK Negeri Pembina Ciawigebang.
\end{abstract}

Kata kunci: Media Flipchart, Kemampuan Membaca, Anak Usia Dini 


\section{PENDAHULUAN}

Membaca adalah suatu kemampuan untuk melihat lambang-lambang tertulis serta mengubah lambang-lambang tertulis tersebut melalui fonic atau ucapan menjadi/menuju bahasa lisan. Membaca merupakan jendela yang paling luas untuk menguasai pengetahuan. Membaca dapat memperluas pengalaman anak, membuka pengetahuan yang ada dihadapannya, memberikan hiburan dan kesenangan dan membantu memecahkan masalah. Kegemaran membaca harus dikembangkan sejak dini, bahkan membaca merupakan permainan yang menyenangkan bagi anak usia dini. Anak yang sudah memiliki kesiapan membaca di TK akan lebih percaya diri dan penuh kegembiraan. Jadi kemampuan membaca dapat dikembangkan di TK. seperti yang dikemukakan oleh Moleong (2003) salah satu aspek yang harus dikembangkan di TK adalah kemampuan membaca.

Kemampuan membaca sangat penting dimiliki anak karena, anak yang senang membaca akan membaca dengan baik, sebagian waktunya digunakan untuk membaca. Membaca akan memberikan wawasan yang lebih luas dalam segala hal, dan membuat belajar lebih mudah. Anak yang gemar membaca dihadapkan pada suatu dunia yang penuh dengan kemungkinan dan kesempatan agar mampu mengembangkan pola berpikir kreatif dalam diri mereka.

Untuk menjadikan anak mampu membaca dengan baik yang harus dilakukan oleh orang tua dan guru salah satunya adalah memilih media yang tepat dalam mengajarkan membaca. Pembelajaran mengandung arti setiap kegiatan yang dirancang untuk membantu seseorang mempelajari suatu kemampuan dan atau nilai yang baru. Pembelajaran sebagai proses belajar yang dibangun oleh guru untuk mengembangkan kreativitas berpikir yang dapat meningkatkan kemampuan berpikir siswa serta dapat meningkatkan kemampuan mengkonstruksi pengetahuan baru sebagai upaya meningkatkan penguasaan yang baik terhadap materi pelajaran. Kegiatan pembelajaran pada dasarnya merupakan proses komunikasi dua arah. Dalam proses komunikasi tersebut guru bertindak sebagai komunikator yang bertugas menyampaikan pesan pembelajaran kepada penerima pesan yaitu anak didik. Agar pesanpesan pembelajaran yang disampaikan guru dapat diterima dengan baik oleh anak didik maka dalam proses komunikasi pembelajaran diperlukan media penyalur pesan yang disebut media pembelajaran.

Berdasarkan latar belakang penelitian dan pembatasan penelitian di atas, penulis merumuskan beberapa masalah sebagai berikut:

1. Bagaimanakah kemampuan membaca anak usia dini Kelompok B TK Negeri Pembina Ciawigebang sebelum penerapan media flipchart?

2. Bagaimana penerapan media flipchart dalam pembelajaran membaca anak usia dini Kelompok B TK Negeri Pembina Ciawigebang?

3. Bagaimana pengaruh media flipchart terhadap kemampuan membaca anak usia dini di Kelompok B TK Negeri Pembina Ciawigebang?

\section{METODE}

Sesuai karakteristik permasalahan dalam penelitian ini, maka jenis penelitian ini adalah penelitian kuantitatif dengan metode eksperimen. Penelitian kuantitatif dapat diartikan sebagai metode penelitian yang berlandaskan pada filsafat positivisme, digunakan untuk meneliti pada populasi atau sampel tertentu, teknik pengambilan sampel pada umumnya dilakukan secara random, pengumpulan data bersifat kuantitatif/statistik dengan tujuan untuk menguji hipotesis yang telah ditetapkan.

Penelitian kuantitatif dipilih karena data yang diperoleh adalah data-data yang berupa angka-angka yang membutuhkan pengujian statistik untuk menguji bagaimana pengaruh media Flipchart dalam meningkatkan kemampuan membaca anak usia dini di 
kelompok B TK Negeri Pembina Ciawigebang.

Metode penelitian eksperimen dapat diartikan sebagai metode penelitian yang digunakan untuk mencari pengaruh perlakuan tertentu terhadap yang lain dalam kondisi yang terkendalikan.

\section{Rancangan Penelitian}

Rancangan dalam penelitian ini adalah dengan menggunakan one-group pretest and posttest design. Untuk mengetahui kemampuan membaca anak sebelum penerapan media flipchart maka digunakanlah tes awal (pretest). Tes akhir (post-test) dimaksudkan untuk mengetahui kemampuan membaca anak sesudah penerapan media flipchart. Adapun rancangan atau design ini dapat digambarkan sebagai berikut:

$\mathrm{O}_{1} \mathrm{X} \mathrm{O}_{2}$

Keterangan:

$\mathrm{O}_{1}=$ nilai pre-test (sebelum penerapan media flipchart)

$\mathrm{X}=$ perlakuan

$\mathrm{O}_{2}=$ nilai post-test (setelah penerapan media flipchart)

\section{Teknik Penentuan Populasi dan Sampel}

Populasi diartikan sebagai wilayah generalisasi yang terdiri atas obyek/subyek yang mempunyai kualitas dan karakteristik tertentu, yang ditetapakan oleh peneliti untuk dipelajari dan kemudian ditarik kesimpulannya.

Sampel adalah sebagian dari populasi itu. Adapun sampel dalam penelitian ini adalah seluruh anak kelompok B TK Negeri Pembina Ciawigebang kecamatan Ciawigebang Kabupaten Kuningan yang berjumlah 24 siswa. Teknik sampling yang digunakan adalah sampling jenuh yaitu teknik penentuan sampel bila semua anggota populasi digunakan sebagai sampel. Hal ini sering dilakukan bila jumlah populasi relatif kecil, kurang dari 30 orang, tua penelitian yang ingin membuat generalisasi kesalahan yang sangat kecil.

\section{Teknik Pengumpulan Data}

Pengumpulan data dalam penelitian ini dilakukan dengan teknik pengumpulan data sebagai berikut :

a. Observasi

Observasi yaitu melakukan pengamatan secara langsung ke objek penelitian untuk melihat dari dekat kegiatana yang dilakukan. Lembar observasi digunakan untuk memperoleh data aktivitas anak melalui pengamatan selama proses pembelajaran berlangsung yang diisi oleh observer.

b. Tes

Teknik tes dalam penelitian ini adalah teknik pengumpulan data yang hasilnya akan diolah dengan analisis statistik. Dengan menggunakan skala pengukuran ranting-scale yaitu data mentah yang diperoleh berupa angka kemudian ditafsirkan dalam pengertian kualitatif. Ranting-scale lebih fleksibel, tidak terbatas untuk pengukuran sikap saja tetapi untuk mengukur persepsi responden terhadap fenomena lainnya. Seperti pengetahuan, kemampuan, proses kegiatan dan lain-lain.

Teknik tes dalam penelitian ini adalah teknik pengumpulan data utama yang hasilnya akan diolah dengan analisis statistik. Data tes berupa tes awal (pre-test) dan tes akhir (posttest) terhadap siswa yang menjadi sampel penelitian. Tes awal (pre-test) dimaksud untuk mengetahui kemampuan membaca anak sebelum penerapan media flipchart. Tes akhir (post-test) dimaksudkan untuk mengetahui kemampuan membaca anak sesudah penerapan media flipchart.

Teknik tes yang akan dilaksanakan di TK Negeri Pembina Ciawigebang adalah sebagai berikut:

1) Pemberian lembar kerja anak dengan kegiatan melingkari huruf vokal,

2) Pemberian lembar kerja anak dengan kegiatan melengkapi huruf konsonan,

3) Pemberian lembar kerja anak dengan kegiatan melingkari gambar buah yang suku kata awalnya sama.

4) Pemberian lembar kerja anak dengan kegiatan menuliskan nama buah sesuai gambar buahnya, 
5) Pemberian lembar kerja anak dengan kegiatan menghubungkan gambar buah dengan tulisannya,

c. Dokumentasi

Metode dokumentasi, yaitu mencari data mengenai hal-hal atau variablel yang berupa catatan, transkrip, buku, surat kabar, majalah, prasasti, notulen rapat, lengger, agenda, dan sebagainya.

d. Instrumen Penelitian

Instrumen penelitian adalah alat bantu dalam pengumpulan data. Maka dalam menggunakan metode observasi instrumennya adalah sebagai berikut:

Tabel 3.5

Kisi-kisi instrumen

Variabel X : Media Flipchart

\begin{tabular}{|c|c|}
\hline Subvariabel & Indikator \\
\hline $\begin{array}{l}\text { 1. Media flipchart } \\
\text { dapat digunakan } \\
\text { dalam membantu } \\
\text { tercapainya tujuan } \\
\text { pembelajaran. }\end{array}$ & $\begin{array}{l}\text { a. } \\
\text { Kemampuan } \\
\text { membaca anak } \\
\text { usia dini. }\end{array}$ \\
\hline $\begin{array}{l}\text { 2. Media flipchart } \\
\text { relevan dengan } \\
\text { kompetensi yang } \\
\text { ingin dicapai. }\end{array}$ & $\begin{array}{l}\text { b. Menyebutkan } \\
\text { huruf vokal } \\
\text { dan konsonan. } \\
\text { c. Membedakan } \\
\text { kata-kata yang } \\
\text { mempunyai } \\
\text { suku kata awal } \\
\text { yang sama. } \\
\text { Membaca } \\
\text { gambar yang } \\
\text { memiliki kata / } \\
\text { kalimat } \\
\text { sederhana. }\end{array}$ \\
\hline $\begin{array}{l}\text { 3.Media flipchart dapat } \\
\text { menimbulkan gairah } \\
\text { dan motivasi dalam } \\
\text { belajar. }\end{array}$ & $\begin{array}{l}\text { a. Anak mau } \\
\text { bertanya dan } \\
\text { dapat } \\
\text { menjawab }\end{array}$ \\
\hline
\end{tabular}

\begin{tabular}{|c|c|c|}
\hline & & $\begin{array}{l}\text { pertanyaan } \\
\text { guru }\end{array}$ \\
\hline $\begin{array}{l}\text { 4.Media flipchart dapat } \\
\text { meningkatkan sikap } \\
\text { aktif siswa dalam } \\
\text { belajar. }\end{array}$ & $b$ & $\begin{array}{lr}\text { Contoh } & \text { yang } \\
\text { diberikan } & \text { guru } \\
\text { cukup } & \text { dan } \\
\text { jelas. } & \\
\text { Latihan yang } \\
\text { diberikan guru } \\
\text { cukup dan } \\
\text { jelas. Anak } \\
\text { mengerti } & \text { pesan } \\
\text { pembelajaran } \\
\text { yang } \\
\text { disampaikan } \\
\text { guru }\end{array}$ \\
\hline
\end{tabular}

Kisi-kisi Instrument Variabel Y.

\begin{tabular}{|c|c|}
\hline Subvariabel & Indikator \\
\hline $\begin{array}{l}\text { a. Menyebutkan } \\
\text { simbol-simbol } \\
\text { huruf vocal yang } \\
\text { dikenal di } \\
\text { lingkungan sekitar }\end{array}$ & $\begin{array}{l}\text { a. Anak dapat } \\
\text { menyebutkan } \\
\text { simbol-simbol } \\
\text { huruf vokal. }\end{array}$ \\
\hline $\begin{array}{l}\text { b. Menyebutkan } \\
\text { simbol-simbol } \\
\text { huruf konsonan } \\
\text { yang dikenal di } \\
\text { lingkungan sekitar }\end{array}$ & $\begin{array}{l}\text { a. Anak dapat } \\
\text { membedakan } \\
\text { suara huruf awal. }\end{array}$ \\
\hline $\begin{array}{l}\text { c. Membedakan nama } \\
\text { benda yang suara } \\
\text { huruf awalnya } \\
\text { sama }\end{array}$ & $\begin{array}{l}\text { a. Anak dapat } \\
\text { membedakan } \\
\text { suara huruf awal. }\end{array}$ \\
\hline $\begin{array}{l}\text { d. Membaca gambar } \\
\text { yang memiliki kata } \\
\text { / kalimat sederhana }\end{array}$ & $\begin{array}{l}\text { b. Anak dapat } \\
\text { membedakan } \\
\text { nama benda yang } \\
\text { suara huruf }\end{array}$ \\
\hline
\end{tabular}




\begin{tabular}{|c|c|}
\hline & awalnya sama \\
\hline 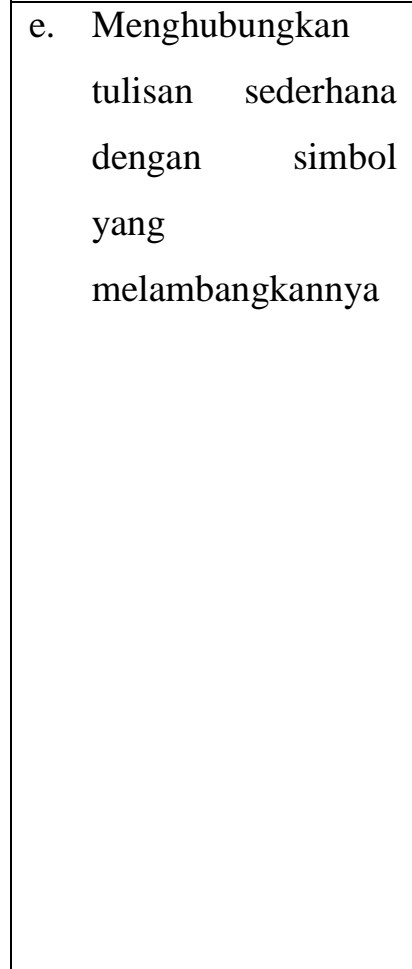 & $\begin{array}{l}\text { a. Anak dapat } \\
\text { membaca } \\
\text { gamabar. } \\
\text { b. Anak dapat } \\
\text { membaca kata } \\
\text { sederhana. } \\
\text { c. Anak dapat } \\
\text { membaca kalimat } \\
\text { sederhana. } \\
\text { d. Anak dapat } \\
\text { membaca } \\
\text { gambar yang } \\
\text { memiliki kata/ } \\
\text { kalimat } \\
\text { sederhana }\end{array}$ \\
\hline
\end{tabular}

\section{Teknik Analisis}

e. Analisis Uji Data Penelitian

Prosedur analisis data dalam penelitian adalah menggunakan desain pre-test dan posttest Group. Membuat prosedur pengolehan data dalam sebuah penelitian sangatlah penting dan agar lebih mudah dalam pengolahan data hasil penelitian. Maka prosedur pengolahan data dalam penelitian ini adalah sebagai berikut:

1. Analisis Skor Ideal

Kriteria skor ideal akan membagi keadaan suatu data menjadi tiga kategori, yaitu: tinggi/kuat, sedang, dan kurang/rendah. Ketiga kategori dapat digunakan untuk membuat kesimpulan.

Adapun rumus yang digunakan untuk mengukur Kriteria Skor Ideal menurut Riduan adalah :

Dalam penelitian variabel $\mathrm{X}$ dan variabel $\mathrm{Y}$ dibagi menjadi tiga kategori yang didasarkan pada kriteria ideal dengan rumus sebagai berikut:

a. Kategori I : Berada pada luas daerah kurva sebesar $27 \%$ atau sebesar
0,73 kurva normal dengan $\mathrm{z}=0,61$,

b. Kategori II : Berada pada luas daerah kurva sebesar $46 \%$ atau sebesar 0,72 kurva normal dengan $\mathrm{Z}=+0,61$.

c. Kategori III : Berada pada luas daerah kurva sebesar $27 \%$ atau 0,23 kurva normal dengan $\mathrm{z}=\mathbf{-} 0,61$.

Jika dikonferensikan dengan rumus di atas, maka didapat kriteria sebagai berikut:

$\mathrm{X} \geq \mathrm{Xid}+0,61 \mathrm{sd}$ adalah tinggi/baik

$\mathrm{Xid}-0,61 \mathrm{Xsd}<\mathrm{X}<\mathrm{Xid}+0,61$ sd adalah sedang

Xid $\leq$ Xid-0,61 sd adalah kurang.

2. Uji Normalitas distribusi data

Berdasarkan permasalahan yang menulis temukan dalam penelitian ini. Maka untuk menjawab permasalahan tersebut, penulis menggunakan pengolahan data dengan menggunakan perhitungan statistik.

Langkah 1. Mencari skor terbesar dan terkecil

Langkah 2. Mencari nilai Rentangan (R)

$\mathrm{R}=$ Skor terbesar - Skor

terkecil

Langkah 3. Mencari Banyaknya Kelas (BK)

$$
\mathrm{BK}=1+3,3 \log \mathrm{n} \text { (Rumus }
$$

\section{Sturgess)}

Langkah 4. Mencari nilai panjang kelas (i) Langkah 5. Membuat tabulasi dengan tabel penolong

Langkah 6. Mencari rata - rata (mean)

Langkah 7. Mencari simpangan baku (standar deviasi)

Langkah 8. Membuat daftar frekuensi yang diharapkan dengan cara:

a. Menentukan batas kelas, yaitu angka skor kiri kelas interval pertama dikurangi 0,5 dan kemudian angka skor-skor kanan kelas interval ditambah 0,5 .

b. Mencari nilai Z-score untuk batas kelas interval dengan rumus: 
c. Mencari luas $0-\mathrm{Z}$ dari Tabel Kurve Normal dari $0-Z$ dengan menggunakan angka-angka untuk batas kelas.

d. Mencari luas tiap kelas interval dengan cara mengurangkan angka-angka $0-\mathrm{Z}$ yaitu angka baris pertama dikurangi baris kedua, angka baris kedua dikurangi baris ketiga, dan begitu seterusnya, kecuali untuk angka yang berbeda pada baris paling tengah ditambahkan dengan angka pada baris berikutnya.

e. Mencari frekuensi yang diharapkan (fe) dengan cara mengalikan luas tiap interval dengan jumlah responden $(n=64)$.

Langkah 9. Mencari Chi-kuadrat hitung (x2 hitung)

Langkah 10. Membandingkan x2 hitungan dengan $\mathrm{x} 2$ tabel

Dengan membandingkan $\mathrm{x} 2$ hitung dengan nilai $\mathrm{x} 2$ tabel untuk $\alpha=0,05$ dan derajat kebebasan $(\mathrm{dk})=\mathrm{k}-1=7-1=6$, maka dicari pada tabel Chi-kuadrat didapat x2 tabel $=12,592$ dengan kriteria pengujian sebagai berikut:

Jika X2 hitung $\geq X 2$ tabel, berarti Distribusi Data Tidak Normal dan Jika X2 hitung $\leq \mathrm{X} 2$ tabel, berarti Data Berdistribusi Normal.

3) Uji Homogenitas Varian

Uji homogenitas varian digunakan untuk mengetahui apakah kedua kelas yaitu kelas eksperimen dan kelas kontrol mempunyai varian yang sama atau tidak.

Langkah 1. Mencari nilai varian terbesar dan varian terkecil dengan rumus :

Langkah 2. Membandingkan nilai Fhitung dengan $\mathrm{F}$ tabel, dengan rumus

$=11$ (untuk varian terbesar)

$$
\mathrm{dk} \text { pembilang }=\mathrm{n}-1=12-1
$$

dk penyebut $=\mathrm{n}-1=11-1=$

10 (untuk varian terkecil)

Dengan kriteria pengujian sebagai berikut:

Jika F hitung $\geq F$ tabel, berarti Tidak Homogen dan

Jika F hitung $\leq \mathrm{F}$ tabel, berarti

Homogen.
4) Uji Hipotesis (Uji t)

Untuk menguji kebenaran hipotesis penulis menggunakan rumus uji t. Adapun rumusnya secara teoritis adalah sebagai berikut:

a. Keterangan :

Md = mean dari perbedaan pre test dengan post test (post test - pre test).

$\mathrm{Xd} \quad=$ deviasi masing-masing subjek ( $\mathrm{d}$ $\mathrm{Md})$

$\sum \mathrm{x} 2 \mathrm{~d}=$ jumlah kuadrat deviasi

$\mathrm{N} \quad=$ subjek pada sampel

d.b. = ditentukan dengan $\mathrm{N}-1$

b. Menentukan nilai $t$ dengan taraf kepercayaan yang dipilih $5 \%(0,05)$

c. Pengujian hipotesis dengan kriteria sebagai berikut :

1) Jika t hitung $\geq$ tabel maka hipotesis diterima

2) Jika t hitung $\leq$ tabel maka hipotesis ditolak.

\section{HASIL DAN PEMBAHASAN}

Berdasarkan hasil penelitian yang telah penulis lakukan tentang efektivitas media flipchart dalam meningkatkan kemampuan membaca anak usia dini di Kelompok B TK Negeri Pembina Ciawigebang, dapat diambil simpulan sebagai berikut :

1. Hasil uji coba nilai kemampuan membaca anak Kelompok B di TK Negeri Pembina Ciawigebang dari hasil pre-test yang dilakukan pada 24 orang siswa tergolong cukup, hal tersebut terbukti dengan diperolehnya nilai rata-rata mencapai 10,8 dan yang mencapai nilai 12 ke atas hanya 6 orang.

2. Hasil observasi menunjukkan bahwa pembelajaran dengan menggunakan media flipchart diperoleh jumlah skor nilai 16 apabila persentase mencapai $80 \%$. Artinya media flipchart sangat baik digunakan dalam pembelajaran membaca anak usia dini di Kelompok B Tk Negeri Pembina Ciawigebang.

3. Hasil perhitungan menunjukkan bahwa terdapat perbedaan yang signifikan pada kemapuan membaca anak usia dini, yakni nilai kemampuan membaca anak 
Kelompok B di TK Negeri Pembina Ciawigebang dari hasil pre-test rataratanya 10,8 dan ketika diberikan post-test setelah menggunakan media flipchart dalam pembelajaran membaca diperoleh nilai rata-rata 13 dan hasil perghitungan nilai t hitung

dibanding ttabel $\neg$ diperoleh hasil nilai thitung $=12,99$ dari nilai tatabel $=2,07$ artinya tolak Ho dan Ha diterima.

Dengan demikian Media flipchart berpengaruh positif terhadap kemampuan membaca anak usia dini Kelompok B TK Negeri Pembina Ciawigebang.

\section{DAFTAR PUSTAKA}

Arikunto, Suharsimi. 2013. Prosedur Penelitian Suatu Pendekatan Praktik. Jakarta : PT. Rineka Cipta.

Arsyad, Azhar. 2014. Media Pembelajaran. Jakarta : Rajawali Pers.

Aulia. 2012. Revolusi Pembuat Anak Candu Membaca. Jogjakarta : FlashBooks.

Dhieni, Nurbiana. 2008. Metode Pengembangan Bahasa. Jakarta : Universitas Terbuka.

Indiana, Dina. 2011. Ragam Alat Bantu Media Pengajaran Mengenal, Merancang, dan Mempraktikannya. Yogyakarta : Diva Press.

Jamaris, Martini. 2006. Perkembangan dan Pengembangan Anak Usia Taman Kanak-Kanak. Jakarta : PT. Gramedia Widiasarana Indonesia.

Latif, Mukhtar. 2013. Orientasi Baru Pendidikan Anak Usia Dini Teori dan Aplikasi. Jakarta : Kecana Prenada Media Group.

Hariyanto, Agus. 2009. Membuat Anak Anda Cepat Pintar Membaca. Jogjakarta : DIVA Press.

Riduwan. 2013. Belajar Mudah Penelitian Untuk Guru - Karyawan dan Peneliti Pemula. Bandung : Alfabeta.

Rudi Susilana dan Cepi Riyana. 2007. Media Pembelajaran Hakikat, Pengembangan. Pemanfaatan dan penilian. Bandung : CV. Wacana Prima.
Sadiman, Arief S. 2012. Media Pendidikan Pengertian, Pengembangan, dan Pemanfaatannya. Jakarta : PT. Raja Grafindo Persada.

Sudjana, Nana dan Rivai, Ahmad.2011. Media Pengajaran. Bandung : Sinar Baru Algensindo Offset.

Sugiyono. 2012. Metode Penelitan Kuantitatif Kualitatif dan R \& D. Bandung : CV. Alfabeta.

Tampubolon. 1993. Mengembangkan Minat dan Kebiasaan Membaca Pada Anak. Bandung : Angkasa.

Tarigan, Hendry Guntur. 2008. Membaca Sebagai Suatu Keterampilan Berbahasa. Bandung : Angkasa.

Toha, M. Anggoro. 2008. Metode Penelitian. Jakarta : Universitas Terbuka.

Undang-Undang tentang Sistem Pendidikan Nasional.

Winataputra, Udis. S. 2007. Teori Belajar dan Pembelajaran. Jakarta : Universitas Terbuka.

Yunus, Samir. 2006. Menjadikan Anak Senang Membaca. Jakarta : BIC Publishing.

Zaman, Badra dkk.2009. Media dan Sumber Balajar TK. Jakarta : Universitas Terbuka. 